\title{
Computers and policy-making: the CASCON experiment ${ }^{1}$
}

\author{
LINCOLN P. BLOOMFIELD \\ Center for International Studies, Massachusetts Institute of Technology \\ and ROBERT BEATTIE \\ Center for Political Studies, University of Michigan
}

Most observers of US foreign policy decision-making would probably agree that, whatever the virtues or defects of a particular policy choice, the process by which decisions are reached on crisis or incipient crisis situations leaves something to be desired. Despite good intentions, there persists an all-toofrequent tendency to be taken by surprise, to lurch from crisis to crisis, to under-use instruments of preventive diplomacy, and to be faced with situations in which only undesirable military options are available.

The Nixon administration has identified some aspects of this problem, and announced various organizational and methodological means to overcome them. The results to date are, to say the least, not entirely convincing. And while as Americans our first concern is with US policy, the problem is by no means confined to the US decision-making apparatus. Rather, this tendency represents a weakness of governments in general, and of in-

${ }^{1}$ This article reports on research conducted by the Arms Control Project, Center for International Studies, MIT, under the sponsorship of the US Arms Control and Disarmament Agency. The judgments expressed in this report are those of the authors and do not necessarily reflect the views of the United States Arms Control and Disarmament Agency or any other agency of the United States Government. (For a more detailed report see Beattie and Bloomfield, 1969.) ternational organizations such as the United Nations, in anticipating and forfending unwanted and undesirable policy outcomes.

If we define "crisis" as a short-time, highthreat, unexpected political-military situation (Hermann, 1969, p. 29), it is clear what some of the difficulties are for harassed and fallible humans to act in ways that are generally defined as systematic, if not "rational". Surely rational decision-making connotes, at a minimum, processes of information search, comparison or contrast with other experience, and application of principles derived from previously validated propositions.

Anyone who has worked in the crisis business is painfully aware of the customary inadequacy of information; of how other situations seem to be remote or unhelpful; and the way in which curbstone judgments, horseback opinions, and gut reactions constitute invariable substitutes for explicit systematic analysis.

And crises are different and demanding, but because of the exigent nature of crises, advance planning becomes even more a necessity. Yet in the American policy community, many of the needful arts of the systematic policy planner-anticipating, forecasting, acting preventively, preparing contingent plans-have been treated at best on suffrance, at worst as exotic and harmfully 
"theoretical" deviations from the routineincluding the "crisis routine." (A separate treatise is needed on the low estate to which US foreign policy planning has in fact fallen in recent times, despite increased attention to "systems" approaches and National Security Council activity.) ${ }^{2}$

Let us sharpen our definition of the problem inherent both in crisis and pre-crisis management, with the understanding that while we focus on US policy-making, the problem exists with other governments and international organizations as well.

We see four major shortcomings: (a) crises are invariably coped with late rather than early in their development; (b) each situation is usually looked upon as unique; (c) no general theory is accepted as applying to crisismanagement; and (d) it is difficult to gather information on the crisis or related crises at a time when it is most needed. To alleviate these problems policy analysts or planners need four kinds of solutions: (a) better means of planning for crises early in their development; (b) a way of comparing new, incipient crisis situations with other situations to find useful similarities; (c) a general theory or model to help explain and predict to crises; and (d) a fast and easy-to-use mechanism to obtain needed information.

As a modest or experimental attempt to bring to bear on these problems some of the methods and tools of contemporary social science, including that of computer technology, we developed at MIT a Computer-Aided Sys-

\footnotetext{
${ }^{2}$ For confirmation, note the abolition of the Policy Planning Council in the State Department and criticisms leveled in Toward a Modern Diplomacy (American Foreign Service Association, 1968). In both government and academe some devices such as simulation have been used to try to fill in at least some of the gaps (for the present authors' recent involvement see Bloomfield et al., 1970). For other simulation approaches to policy problems, see those covered in Raser, 1969, as well as various earlier works by inter alia Harold Guetzkow and the present senior author.
}

tem for Handling Information on Local Conflicts (CASCON).

\section{The Model of Conflict}

CASCON is a computerization of the principal features of the Model of Local Conflict $^{3}$ Dynamics and Control developed by Bloomfield and Leiss (1969; hereafter referred to as Design Study. See also Bloomfield and Leiss, 1970, and Barringer, 1967). That model of local conflict provides CASCON with its basic concepts. Above all, the primary concern of both the Design Study that generated the model and case data, and of the subsequent CASCON computer experiment, was policy utility, in the sense of seeking to contribute, however modestly, to improving realworld responses to new conflict situations by the US, by multilateral agencies such as the United Nations, or by the other principal actors in crisis diplomacy.

The primary object of the Design Study was neither theory-building, pure methodology nor comprehensiveness of the data basealthough all three figured in the research. In developing their original model, Bloomfield and Leiss examined the contemporary literature dealing with the problems of local conflict and its management. None of the models or theories examined seemed to provide the insights needed to develop a model that would both explain the process of local conflicts (as observed in the world) and suggest ways of resolving such conflicts.

Authors such as Kenneth Boulding note that conflicts ". . . take place in time and consist of a succession of states of a situation or field" (1963, p. 19). He further says, “. . . the succession of states of a social system is not random; some regularities can usually be detected . . ." (p. 19). This idea is central to the MIT model. Also found in the Bloomfield

${ }^{3} \mathrm{~A}$ local conflict is defined as "a small war or potentially military clash within or between all but the major powers." 
and Leiss model is the notion of dealing with conflicts early in their development. Boulding states, "Conflict situations are frequently allowed to develop to almost unmanageable proportions before anything can be done about them, by which time it is often too late to resolve them by peaceable or procedural means. To catch conflicts young, however, means that dynamic social processes which lead to ultimate breakdown have to be publicly identifiable: we cannot deal with invisibles" (Boulding, 1962, p. 325).

In addition to the ideas of conflict as process and of early treatment of conflicts, the concept of identifiable phases of conflict is found in several works. Oran Young, writing the year following the MIT model development, argues that "perhaps the most important concept ... concerns the phase of a given crisis and the consequent possibility of discussing its life cycle. Clearly, crises do not form homogeneous systems that remain unchanging from start to finish" (Young, 1968, p. 18). Young also considers the concept of factor. He states,". . . crises tend to pass through a series of more delicately defined phases arising from changes in such factors as: the evaluations of the participants about the course of the crisis; the proximate objectives of the various parties; credibility and strength of resolve or political will; mutual analysis of the opponent's expectations; appraisals concerning the costs of giving in compared to the costs of continuing; and nonrational influences"' (p. 18). Young also notes "while the temporal dimension is an important one, it is also necessary to treat the problem of phases in terms of underlying shifts of analytic significance rather than simple sequential descriptions" (1968, p. 19). Quincy Wright earlier had suggested four stages of conflict between nations: awareness of inconsistencies; rising tensions; pressures short of military force to resolve inconsistencies; and military intervention or war. He considered as important determinants of whether a case moves from one stage to the next, such factors as: willingness to escalate, perceived national interests involved in conflict, perception of available armed forces, perceptions of cost of hostility, perception of world opinion creating pressures for peace, and perception of vulnerability to destruction (Wright, 1965). The factors identified in the case studies of the MIT Design Study may be thought of as indicators of theoretical factors such as those suggested by Young, Wright, and others.

The Local Conflict Model set forth in the Design Study assumes that a conflict is a sequence of phases of varying durations. Within each phase exist factors-conditions, perceptions, situations, or relationships-that generate conflict-relevant pressures. Some of these pressures tend toward increased conflict, and some tend away from it. The relative strength of these pressures determines whether or not the conflict worsens. Not all situations of conflict move through all phases, but all conflicts can be located at any given time in one phase.

A local conflict originally rises out of a substantive dispute. The dispute may be over territory, legitimacy, ideology, power, race, religion, or whatever. At its outset this dispute over an issue may not necessarily be perceived in military terms by either side. It is waged at the polls, in the courts, in the press, through the UN or other diplomatic media, economically, politically-in short, any way but militarily. A potential conflict under these circumstances is, according to the model, in phase I, dispute.

When at least one party views the solution to the dispute in military terms, the local conflict has intensified and entered phase II, conflict (pre-hostilities). This condition can come about when one side acquires military material; for example, when a disaffected group acquires arms and thus equips itself with the option of pressing its demands by force. A military option could be introduced in a situation of interstate conflict in which 
both sides have standing military establishments, when one side indicates that its military capability is specifically relevant to the dispute. The introduction of a military option does not mean that hostilities have actually occurred, but that they are now more likely, or at least more possible. The local conflict is "more violent", so to speak, in phase II than phase I.

Phase III, hostilities, occurs when one side actually employs military force to resolve the dispute. This does not mean just sporadic or accidental outbursts. It signifies the inflicting of casualties and/or the destroying of property in a systematic way. Moreover, the level of violence can escalate within this phase. The hostilities may spread to wider geographic areas; more participants may become engaged; small-scale skirmishes may burgeon into pitched battles; or a war begun with small arms may develop into one in which the full panoply of weapons in the adversaries' inventories is hurled against opposing forces and, perhaps, civilian targets as well. (For clarity, we reserved the term "escalation" for intensification of hostilities within phase III, and refer to the process in other phases as "intensification".)

If hostilities are terminated, a threshold is crossed to phase IV, conflict (post-hostilities). Fighting no longer occurs as in phase III, but at least one party continues to view the quarrel in military terms. Phase $\mathrm{V}$, dispute (posthostilities), is entered when the dispute is no longer viewed in military terms. However, the issues in the dispute remain. If the sides manage to resolve the issues, or if they cease to care about them, the dispute is settled. The resulting continuum is illustrated in Figure 1.

The Local Conflict Model rests on five basic hypotheses. (A) Local Conflicts have a general common structure rather than being always unique and random phenomena. (B) All conflicts go through the first phase, dispute, and one or more of the three conflict phases (II, III, IV). (C) In each phase factors can be identified; some factors generate pressures that tend to push the conflict across a threshold of transition into another phase; these factors may be countered by other factors generating pressures that tend toward settlement of the basic dispute. (D) Changes in the relationship among these specific factors will alter the likelihood of a conflict undergoing transition from one phase to another. (E) The course of a local conflict can be significantly altered by policy measures aimed at reinforcing violence-minimizing factors and offsetting violence-generating factors.

This last hypothesis needs clarification on two points. First, the conflict-control aspect of the model and the CASCON system is designed to answer in a systematic way the question, "what would one do if the objective were to minimize international violence?" Approximately half of the fifty-seven or so local conflicts since World War II took place between sovereign states. Few would debate the proposition that, given the fearsome potential of local wars to involve the nuclear powers (and even without that possibility), a

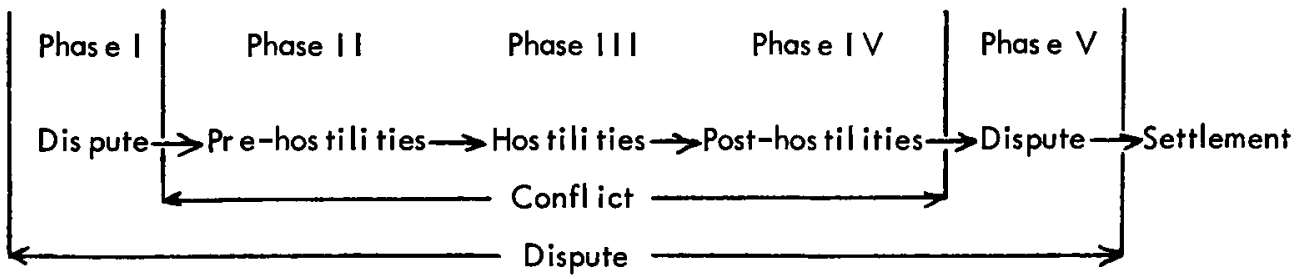

FIG. 1. Phases of the Local Conflict Model. 
concern for peace powerfully supports steps to avert or minimize such wars. In internal conflicts, the potential for nuclear power involvement is of course also present. In these cases a sensible policy aimed at more longterm peace and stability might not invariably attempt to suppress violence, but do precisely what US policy has not always done--i.e., favor the cause of popular government, social justice, and internal political and economic reform; oppose all, not just Communist, forms of tyranny; and accept short-term turbulence, change, and, where appropriate, revolution, in order to lay the foundation for genuine peace. All this comes legitimately under the rubric of conflict-control in the broader sense.

Secondly, the direct connection we have made between conflict-promoting factors and offsetting policy measures may, once said, appear simple and thus obvious. But it has yet to be applied to a purposeful integrated strategy in an age that increasingly appears to be the victim of ungovernable forces, or by a United States that seems less disposed to intervene unilaterally in new crisis situations than in the recent past.

If this general line of reasoning is accepted, its essential simplicity yields to far more complex and sophisticated ideas necessary for its implementation. Just as conflict is a dynamic process and not a single state of affairs, so also conflict control cannot be a single policy objective. Control is composed of several related but distinct objectives which differ from phase to phase.

One control objective is common to every phase, that is, to settle the underlying dispute. But, failing that, there are additional objectives to work toward. Initially, the objective is to keep a dispute (phase I) nonmilitary. Once a military option has been introduced (phase II), the objective is to prevent the outbreak of hostilities and to contain, i.e., restrict the scope/scale of, potential hostilities. If hostilities break out (phase III), the objective is to contain, i.e., moderate, them or terminate them. Once open hostilities are terminated (phase IV), one then wishes to prevent their resumption and, as before, to restrict the scale of potential resumption. If the disputants are pacified to a point where there is no longer any intention by either to seek a military solution (phase V), the objective is to keep it that way.

Control is achieved through measures, i.e., policy actions that can be taken by governments, international organizations, or other groups to offset factors that generate pressures toward violence and reinforce factors that tend away from violence. In phase I, measures are directed at keeping the dispute nonmilitary. In phase II measures are aimed at preventing and containing potential hostilities. In both phases, measures are designed to offset factors that tend toward crossing a threshold to the next phase, or to reinforce factors that tend toward settlement, or at least to prevent the case from moving into the next phase.

In phase III, measures are either to offset factors that prolong or intensify hostilities, or to reinforce factors that tend to terminate or to reduce fighting. Appropriate phase IV measures would be those which offset factors tending back to hostilities, and those which reinforce factors influencing the case to move toward settlement. Figure 2 shows the overall structure.

\section{The CASCON System}

If the assumptions inherent in the Local Conflict Model are accepted, a foreign policy analyst would not consider a new conflict (or dispute) case as necessarily unique. With this model he has the benefit of a crude but apposite theoretical framework to help explain and classify the local conflict process. Further, he would attempt far more purposefully to deal with a potential crisis in its early development, i.e., phase I. One of the most striking 


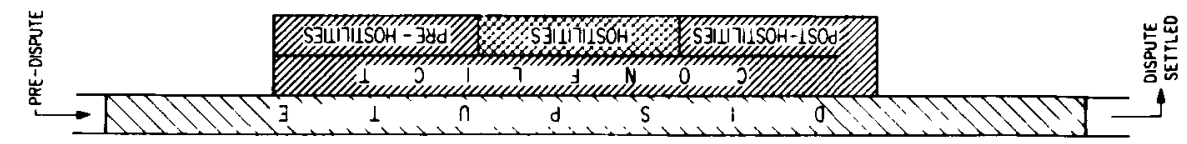

\begin{tabular}{|c|c|c|c|c|c|c|c|c|c|c|}
\hline 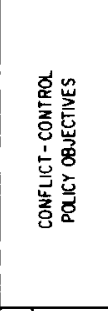 & 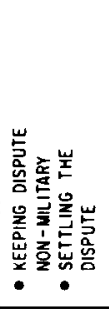 & \multirow{3}{*}{ 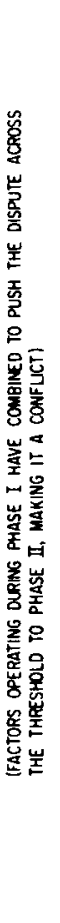 } & 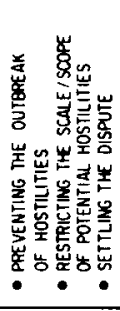 & \multirow{3}{*}{ 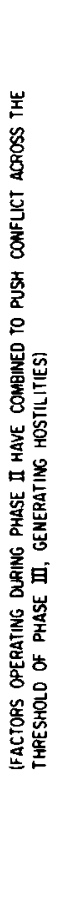 } & 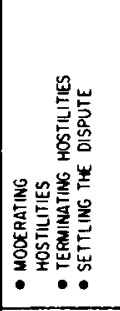 & \multirow{3}{*}{ 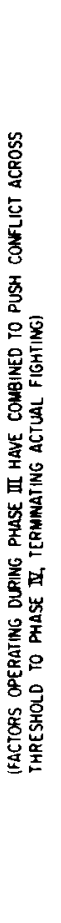 } & 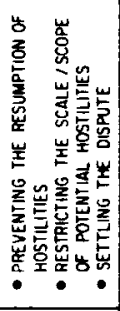 & \multirow{3}{*}{ 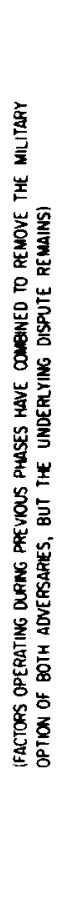 } & 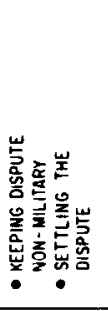 & \\
\hline \multirow{2}{*}{ 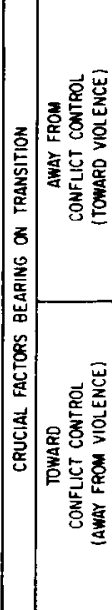 } & 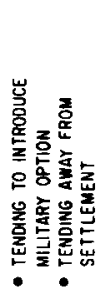 & & 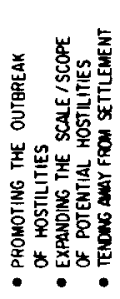 & & 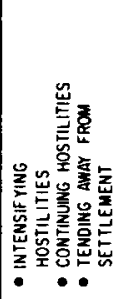 & & 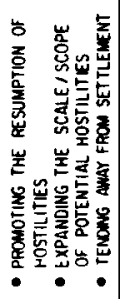 & & 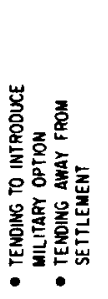 & \\
\hline & 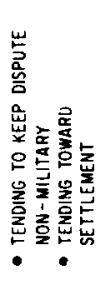 & & 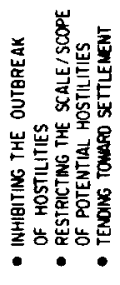 & & 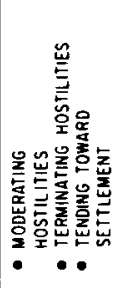 & & 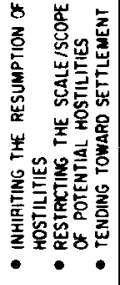 & & 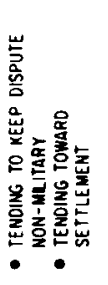 & \\
\hline 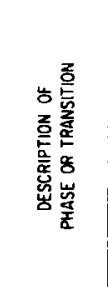 & 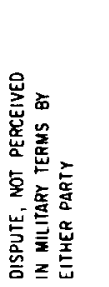 & 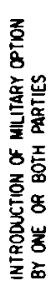 & 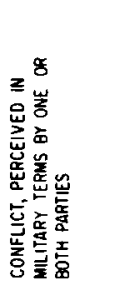 & 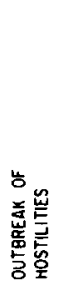 & 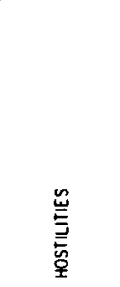 & 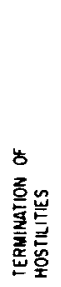 & 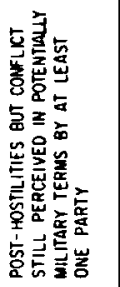 & 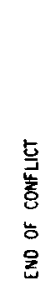 & 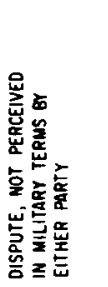 & \\
\hline 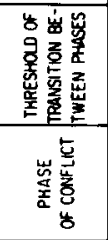 & a & 본 & $\begin{array}{l}a \\
a \\
\alpha\end{array}$ & $\begin{array}{l}\text { 早 } \\
\text { 泉 }\end{array}$ & $\begin{array}{l}\text { 是 } \\
\mathrm{a}\end{array}$ & $\begin{array}{l}\text { 澘 } \\
\text { 昌 }\end{array}$ & $\begin{array}{l}\text { 目 } \\
\text { a }\end{array}$ & I & $\begin{array}{l}1 \\
a\end{array}$ & \\
\hline
\end{tabular}

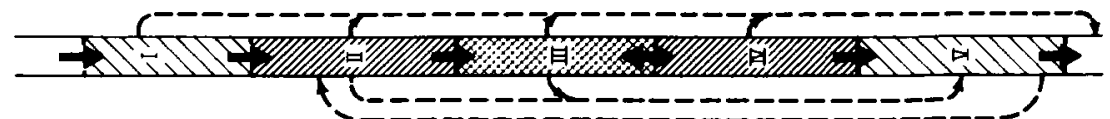


things about our analysis is how diverse and more versatile the catalogue of conflict controlling measures is in phase $I$ than in phase III, by which time options have shrunk just at the time policy-makers finally become focused on a crisis.

However, knowing that a new case may not be unique is hardly enough. The analyst is still faced with problems of information handling. Moreover, his operational style still puts a premium on crisis-management rather than early warning. The research reported here rests on the conviction that the Local Conflict Model, linked to a timesharing computer system, can supply a potentially workable and acceptable tool for resolving some of those dilemmas. ${ }^{4}$

The utility of a time-sharing system is that any single user is given the impression that he has unhampered access to the computer while in reality up to thirty or so users can simultaneously make use of it. Because computers can react infinitely faster than humans, during the moments a user is thinking and communicating to the computer, the computer is moving on to the next operation. Because of the extraordinary speed of operation the user has almost instantaneous feedback, and from his standpoint is interacting in what appears to be real time. It is the timesharing capability of present-day high-speed computers that makes CASCON feasible.

It cannot be emphasized too strongly that such a system is by no stretch of the imagination conceived or intended as a substitute for the indispensable human experience, judgment, and intuition that must inform crucial policy decisions. What is asserted is that, properly used, it can serve as an aid to the memory of the decision-maker by bringing

${ }^{4}$ Credit should be given to John J. Davis, in his former capacity of Assistant Director of the US Arms Control and Disarmament Agency, Weapons Evaluation and Control Bureau, for encouraging the authors to attempt to make that linkage. before him, in rapid and useful fashion, pertinent experience of the past (while hopefully also encouraging him to consider the lessons of the past early, rather than late, in a crisis). It can serve as an aid to his imagination by setting before him suggestive policy measures that, on the basis of comparison, might be relevant to his new problem, and thus might stimulate him to consider or to recommend a wider and more comprehensive range of conflict-avoiding and peace-promoting options.

\section{Computerizing the Model}

Bloomfield and Leiss in their earlier work (1967) applied the Local Conflict Model to some fourteen cases of local conflict. ${ }^{5}$ The factors that were identified phase by phase were all "case-specific". That is, the factors discovered in, e.g., the India-China case were derived from that conflict. Such specific factors, while of obvious value in understanding a given case, are by definition not applicable in that form to a different case. But each casespecific factor could be generalized so that it might apply to a variety of other cases.

For example, a factor specific to the IndiaChina case is: "Chinese advances in the Northeast Frontier Agency threatened the Assam oil fields and menaced Indian control of the narrow neck of land that connects Assam to the rest of India." This factor could be generalized to read: "Advances by one side threaten important economic resource area of other side."

For the purpose of translating the case material into a broader framework, each case-specific factor identified in the Design Study was thus generalized for use in CASCON.

\footnotetext{
${ }^{5}$ To make up the twenty-seven cases now in CASCON (see Appendix), thirteen additional cases were researched by Browne and Shaw International Studies Division of Bolt, Beranek and Newman, (cf. Browne and Shaw International Division, 1969).
} 
This of course entails another assumption: there is a large but nevertheless finite number of general factors that are contemporaneously conflict-relevant. The list of general factors that was generated is probably incomplete and is in the process of being improved. It was assumed that an expert on a given case of local conflict, presented with the list of general factors phase by phase, would be able to note the presence or absence of any factor in a given phase, as well as to judge whether the factor tended toward or away from intensified conflict. For a past case in the original study he could validate deductively, as it were, the judgment earlier made inductively about factors. For new cases, he would have a standardized format for "inputting" data about them.

The list of general factors derived from the fourteen cases was divided by phase, with 119 falling in phase I, 110 in phase II, and 178 in phase III. ${ }^{6}$ These general factors were organized into a data-gathering format called a Factor Coding Form. Table 1 is an example of one page of that coding form.

The coding form by itself is useful for storing information. It also provides a way of looking at a new conflict systematically. However, it does not help the policy analyst or desk officer who wishes to look at prior cases and to make comparisons that might lead to suggestive policy ideas. Both to give him a basis for comparison, and for an independently usable conflict data file, a data base of twenty-six past cases was developed. (This is now in process of expansion to fifty-two conflict cases, and hopefully in the future, it will also include a comparable number of cases that never went beyond phase $I$.)

Every general factor was thus coded for each past case by experts who either had been

\footnotetext{
${ }^{6}$ Although the Local Conflict Model has five phases, CASCON in its pilot form is built upon only the first three. The revised codebook contains 144 factors in phase I, 141 in phase II, and 197 in phase III
}

officially involved in the case or had other relevant expertise. In addition we translated into the coding scheme the original caseresearchers' judgments. The process of coding consisted of the following steps. The expert checked off each general factor as being, in his recollection or knowledge, present or absent in the given phase. (If he did not recollect or did not know, he checked "no information.") If the factor was "not present or not true" he so marked his form and moved to the next factor. If a factor was present, the expert had then to decide if it had an effect on the course of the conflict. If it did not, it was coded as "present-no influence." But if he believed that a factor had some effect, the expert had to decide if the effect was toward or away from violence, i.e., toward or away from the next phase. He had also to judge whether the factor had "much", "some", or "little" influence toward or away from violence. Having made the last two decisions, the expert continued to the next factor and went through the same procedure, eventually for all four hundred or so factors. (A past case can, we found, be coded in less than a day by a knowledgeable expert.)

We attempted to have three experts code each case, although in most cases the initial data base reflects the combined judgments of only two competent experts. There was approximately 21 percent disagreement between coders with regard to a factor being present or not, approximately 22 percent disagreement on the degree of influence ("much", "some", or "little"), and approximately 6 percent disagreement on direction of influence (i.e., toward or away from increased violence or intensification of the conflict).

For the purpose of the initial CASCON development, the coding disagreements were resolved in one of two ways. If there was disagreement as to the degree of influence, the factor was coded as "some". For example, if one expert coded a factor as "much" toward intensification in a given case, and the second 


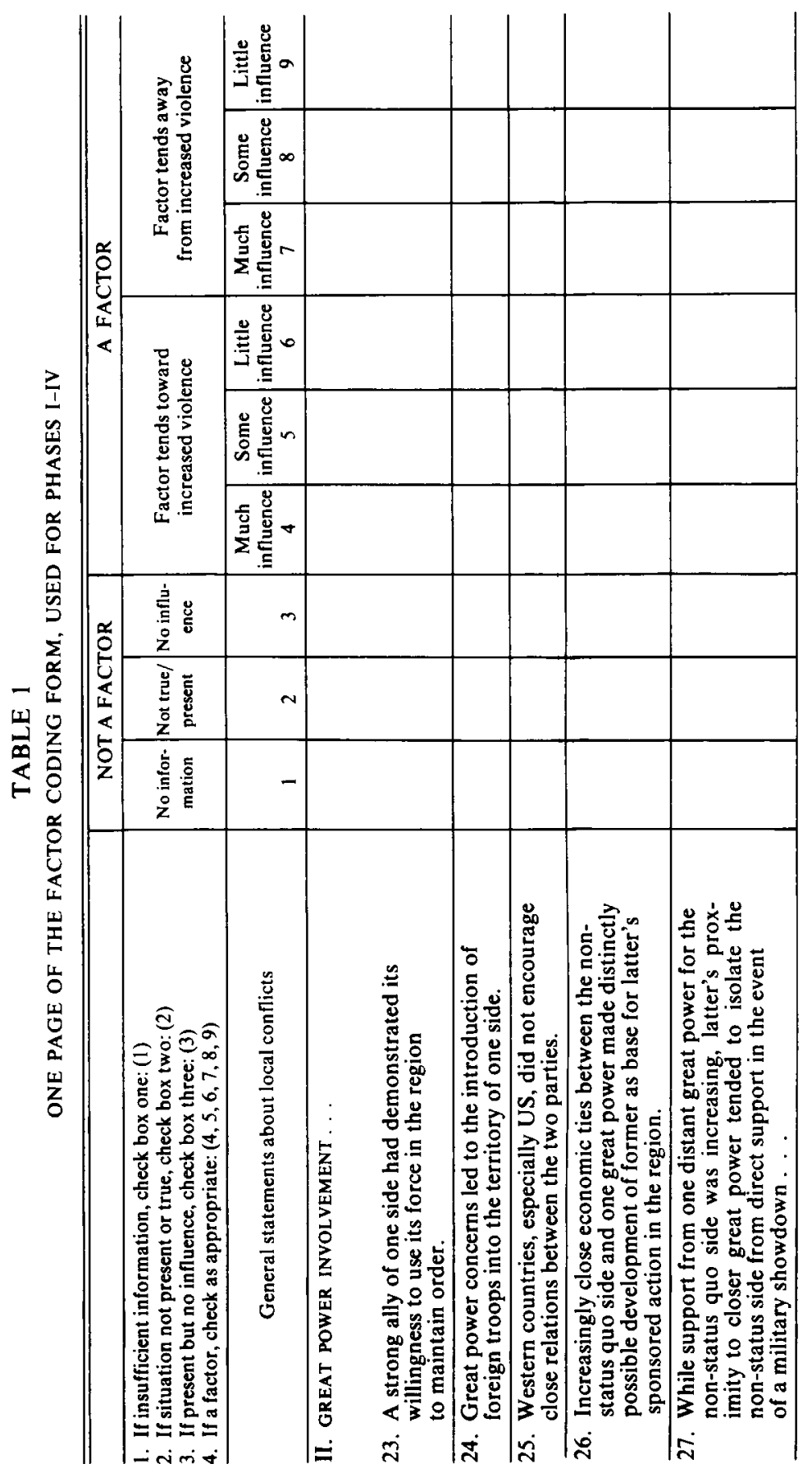


expert coded it as "little," then we assigned that factor an arbitrary score of "some". Thus "much-little", "much-some", "somelittle" are coded as "some". If one expert coded a factor as "much" and another coded the same factor as "no influence", we assigned a code of "some". If one expert coded a factor "no influence", and the other coded it as either "some" or "little", we arbitrarily gave it a value of "little".

For conflicts between expert coders as to direction of effect, i.e., one expert coding "toward" or "away" and the other coding "not present", or one coding "toward" and the other "away", we sought with our colleagues at MIT to reach a consensus opinion. [An alternative method of reconciling the discrepancies could have been to use the raw score of each expert, assign a value to the score ("much" = 3, "some" = 2, etc.) and take an average. The method chosen was the most expedient, and in addition it provided an opportunity for the project staff to examine the data closely.] The coded factors from twenty-six cases, with any differences thus reconciled, became the primary CASCON data base.

\section{Using CASCON}

The analyst who becomes aware of a new dispute or conflict situation now has a framework into which he can record data about the case. Hopefully, it gives him an added inducement to recommend constructive steps at the onset of a dispute rather than at the outbreak of hostilities. The analyst can record the presence or absence of each factor in one of two ways. One way is to fill out a blank coding form. The other way involves using the computer. CASCON is written so that without any special training the analyst can use the on-line interactive capability to help him code his case directly into the computer. Using either mode, he would try to code the effect of each factor toward or away from intensified conflict, and to indicate the degree of that effect. One of the first products of this exercise, in addition to storing case data in instantaneously retrievable form, is that the data is stored in a format geared to the policy objective of conflict control. Furthermore, the case is organized into categories to which the analyst might not normally be sensitive.

Using CASCON, the analyst who inputted the data can now retrieve information about his new case at will, as can any other user of the system. He can also retrieve information on past cases. For example, he can find out in which other past cases a currently interesting factor of phase I was present. He can further retrieve the factors in a particular case that tended toward violence with "much", "some", or "little" influence. Moreover he can review his own case by asking the same kind of questions or by asking for a listing of the factors for which he has no information.

In addition to listing past cases that had some particular factor present and listing particular factors present in specific cases, CASCON will list all factors in a particular category of interest to the user. The factors are grouped under the following category headings: (1) previous or general relations among sides; (2) great power involvement; (3) external relations generally; (4) military-strategic; (5) international organization, legal, public opinion; (6) ethnic (minorities, refugees); (7) economic; (8) internal political; (9) characteristics of one side; (10) communication and information; and (11) actions or controls in the disputed area. Thus a user, who is interested in factors of an economic nature deemed by a panel of historians and experts as conflict-promoting, can find them in CASCON. If he is concerned about the internal political situation in a new case, he can learn from CASCON which internal political factors have been adjudged to be violencepromoting in past situations, and have a print-out of the complete list for use in his own case.

Another way in which CASCON aids the 
analyst's memory is by specifying information gaps in his own case. For example, when he has entered all the factors he knows for a particular case, he can ask CASCON to print out the list of factors coded "no information" and "not present". Such an operation gives a list of items the analyst can use to query potential sources of additional information. In sum, CASCON can provide the analyst a means to "remember" prior conflicts; a systematic way to gather and store information on a current case; and a quick mechanism to generate a list of important questions about the new conflict.

We said earlier that besides being an "aid to memory", CASCON is also an "aid to imagination". The analyst can use the CASCON data base to run a comparison analysis on a new dispute against the information stored as an intermediate step in the "aid to imagination" process. The result of such an analysis gives a list of cases, each scored on the basis of "similarity." By discovering which past cases are "similar" to his current case, a user can examine in detail the factors in those cases, and the conflict-controlling policy measures associated with those factors. $^{\text {? }}$

CASCON's mechanism for "similar" cases deliberately eschewed more sophisticated techniques requiring considerable expertise in statistics to interpret quantitative results. Its "compare to cases" command enables the user to determine which cases in the data-base are most similar to the current case with regard to three measures-“comparability", "information", and "distance". The follow-

${ }^{7}$ The presumption is that the analyst will be stimulated by this process to enrich his own judgmental catalogue of recommendations for ameliorative and constructive actions, particularly if he is given to emphasizing the traditional politicalmilitary categories at the expense of economic, ethnic, communications, and like factors. ing hypotheses are utilized. ${ }^{8}$ (1) Two cases seem "similar" if they have present many of the same factors, and if these factors have the same effect (toward or away from violence). (2) Two cases seem "similar" if in both instances the same "effects" are not present; the crucial similarity is of course in factors, not cases. These two notions are incorporated in the "comparability" statistic. The "information" statistic is designed to measure simply the amount of common information two cases contain. The "distance" statistic allows various hypotheses concerning the relative importance (regarding the notion of "similarity") of factor values to be examined.

The information statistic $\left(\mathbf{I}_{A, B}\right)$ gives an indication of the amount of confidence to be placed in the results of the other two statistics. A low value for this statistic indicates that the two cases (i.e., the current case and the particular data-base case) have information for only a few common factors in the given phase.

The formula for the information statistic (that is, mutual information in cases $A$ and B) is:

$$
\mathbf{I}_{A, B}=\frac{\mathrm{T}_{A, B}}{\mathrm{n}}
$$

where $T_{A, B}$ is the number of factors for which there is information in both cases;

$n$ is the total number of factors in the phase.

The statistic is expressed as a number between 0 and 1; 0 indicates no mutual information and 1 indicates that both cases have mutual information for every factor in the phase.

The comparability statistic $\left(\mathbf{M}_{A, B}\right)$ is designed to generate a value in accord with this theory of comparability. Cases $A$ and $B$ have comparable components if either or both of the following is true: (1) Both A and B have present many of the same factors, and the

\footnotetext{
${ }^{8}$ Cambridge Computer Associates, Cambridge, Mass., provided assistance in developing this solution to the vexing issue of comparability, and did the technical programming of CASCON as well.
} 
coding of these common factors does not show opposite effects (toward or away from violence); and/or (2) Both $A$ and $B$ have many of the same factors not present. The statistic is expressed as a number between 0 and 1 . High comparability $\left(M_{A, B}\right.$ approaches 1) suggests that similar factors are relevant or not relevant in both cases and that there are few factors which affect one case but not the other. Low comparability $\left(\mathrm{M}_{A, B}\right.$ approaches 0 ) suggests that factors are not comparable and that little faith should be placed in the distance statistic.

The formula for comparability is:

$$
\mathbf{M}_{A, B}=\frac{\mathrm{F}_{A, B}-\mathbf{z L}_{A, B}+\mathrm{xN}_{A, B}}{\mathrm{~T}_{A, B}-[1-\mathrm{x}] \mathrm{N}_{A, B}}
$$

where $F_{A, B}$ is the number of factors present (i.e., coded 3-9, see Table 1) in both cases;

$L_{A, B}$ is the number of factors present whose effects tend in opposite directions;

$\mathrm{N}_{A, B}$ is the number of factors not present (i.e., coded 2, see Table 1) in both cases;

$T_{A, B}$ is the number of factors for which there is information (i.e., not coded 1 , see Table 1) in both cases;

$z$ is a coefficient equal to 1 ;

and $x$ is a coefficient equal to .5 .

Note that the coefficients, $z$ and $x$, have the effect of rendering factors not present only half as significant as factors present.

The distance statistic $\left(D_{A, B}\right)$ generates a normalized average factor value difference between two cases. Cases with high average factor value differences tend to be dynamically different; that is, they tend to have the same factors, but these factors contribute different effects (toward or away from violence) or degrees of influence (much, some, or little). Cases with low average factor value differences tend to have the same factors, and these factors make similar contributions to the level of violence.

The distance statistic is expressed as a number between 0 and 1. A distance near zero indicates that the two cases have almost exactly the same factors present, and that these factors have almost exactly the same effects and influences. A distance near 1 indicates that the two cases have few similarities in factors or effects.

The formula for the distance statistic is:

$\mathrm{D}_{A, B}=\sum\left[\frac{\mathrm{USE}[\operatorname{VAL}(i, \mathrm{~A})]-\mathrm{USE}[\operatorname{VAL}(i, \mathrm{~B})]}{\mathrm{F}_{\mathrm{A}, \boldsymbol{B}} \cdot \operatorname{Max}}\right]$

where $F_{A, B}$ is the number of factors present (i.e., coded 3-9) in both cases;

USE[VAL $(i, \mathrm{~A}$ or $\mathrm{B})]$ is the value coded for the $i^{\text {th }}$ factor of case A or case B and replaced (for computational purposes only, no data-change) with the corresponding value from the USE vector (see below); the difference is taken as an absolute, i.e., positive, value;

and Max is the maximum difference between two values in the USE vector (usually the fourth USE vector value minus the seventh USE vector value).

The USE vector is a series of nine numbers with or without signs. In computing the distance statistic, the values from the USE vector replace the corresponding factor code values. Thus, code 1 (no information) is replaced by the first number in the USE vector, code 2 (not present) is replaced by the second number in the USE vector, and so forth.

The system's standard USE vector is:

$$
\mathrm{USE}=\begin{array}{lllllllllll}
0 & 0 & 0 & -1 & -1 & -1 & 1 & 1 & 1
\end{array}
$$

Thus, the first three factor code values $(1=$ no information, $2=$ not present, and $3=$ present, no effect) are rendered ineffective in the computation, and all influences (much, some, or little) toward or away from violence are treated as equally important.

If the user wants to insert his own USE vector he types in nine numbers, with or without signs, for example:

$$
\mathrm{USE}=\begin{array}{llllllllll}
0 & 0 & 0 & 4 & 2 & 1 & -4 & -2 & -1
\end{array}
$$

This USE vector would also nullify the effect of the first factor code values, but it gives greater weight to all "much" influences ("much" is twice as great as "some", "some" is twice as great as "little"). It represents a 
TABLE 2

A HYPOTHETICAL COMPARISON BY USE VECTOR USED TO DERIVE INFORMATION, COMPARABILITY, AND DISTANCE MEASURES

\begin{tabular}{|c|c|c|c|c|}
\hline \multicolumn{2}{|c|}{ Case and dates of conflict } & \multirow{2}{*}{$\frac{\text { Information }}{.14}$} & \multirow{2}{*}{$\frac{\text { Comparability }}{.407}$} & \multirow{2}{*}{$\frac{\text { Distance }}{.444}$} \\
\hline Algeria & $1954-1962$ & & & \\
\hline Algeria-Morocco & $1962-1963$ & .14 & .370 & .150 \\
\hline Angola & $1950-1961$ & .14 & .393 & .421 \\
\hline Bay of Pigs & $1960-1961$ & .14 & .179 & .550 \\
\hline Bolivia & 1967 & .14 & .214 & .607 \\
\hline Cuba & $1957-1959$ & .14 & .418 & .474 \\
\hline Cyprus & $1954-1959$ & .14 & .357 & .471 \\
\hline Dominican Republic & 1965 & 14 & .714 & 048 \\
\hline Greece & $1944-1949$ & .14 & .164 & .733 \\
\hline Guatemala & 1954 & .14 & .148 & .643 \\
\hline India-China & $1954-1962$ & .14 & .370 & .433 \\
\hline Indonesia & $1945-1949$ & .14 & .571 & .273 \\
\hline Indonesia-Malaya & $1963-1965$ & .14 & .382 & .333 \\
\hline Iraq & $1959-1963$ & .14 & .444 & .192 \\
\hline Kashmir & $1947-1949$ & .14 & .273 & .639 \\
\hline Kuwait-Iraq & 1961 & .14 & .296 & .350 \\
\hline Lebanon & 1958 & .14 & .382 & 292 \\
\hline Malaya & $1948-1960$ & .14 & .214 & .625 \\
\hline Philippines & $1948-1954$ & .14 & .214 & .607 \\
\hline Quemoy-Matsu & $1954-1958$ & .14 & .370 & .438 \\
\hline Sinai & 1956 & 14 & 259 & 455 \\
\hline Somalia & $1960-1964$ & .13 & .654 & .275 \\
\hline Soviet-Iran & $1941-1947$ & .14 & .382 & .571 \\
\hline Suez & 1956 & .14 & .259 & .333 \\
\hline Venezuela & $1960-1963$ & 14 & 393 & 214 \\
\hline West Irian & $1962-1963$ & .14 & .382 & .400 \\
\hline Yemen & $1962-1968$ & .14 & .455 & .395 \\
\hline
\end{tabular}

presumption that the degree of influence is a significant element in determining the similarity of effects between two cases.

The results of a hypothetical comparison are illustrated in Table 2 . This result can be used by the analyst in a number of ways. First, he can look at the factors which the most "similar" case has in common with his own. If some important factors in the prior case have yet to appear in the new case, the user can identify those to be averted (or to be promoted if conflict-minimizing). If most factors in the new case are already present, he can look ahead to the next phase of various "similar" cases. This can give him an idea of some possible evolutions of the new case if it were to cross the threshold into the next phase.

Another way that CASCON aids the user's imagination is with regard to measures. A user faced with a new case might want a list of possible measures appropriate for it. For each factor present in the new case, CASCON can print out the corresponding measure. Of course, any given measure may not be appropriate for the new case, and the analyst's judgment, as well as his experience in dealing with the area of the crisis, will come into play in assessing measures. If the measures suggested are obvious, very little time or effort has been lost. If on the other hand, he is given a measure he had not considered before, or not in this context, it might be possible to influence the course of the conflict away from violence, and thus make a contribution to peace. That alone could justify the entire effort.

It is perhaps plainer to the present authors than to anyone else what the limitations, rigidities, and controversial features of the pilot CASCON system are. An effort is now being made to remedy at least some of them. 
Nevertheless, the high degree of interest already shown in CASCON both by governments and by international organization officials, as well as by fellow scholars, points to the belief that CASCON can be improved and perhaps one day made truly operational for the cause of peace.

\section{REFERENCES}

American Foreign Service Association. Toward a Modern Diplomacy. Washington, D.C., 1968.

Barringer, Richard. The Control of Local Conflict: The Conditions of Conflict-A Configural Analysis. Cambridge, Mass.: Center for International Studies, MIT, 1967.

Beattie, Robert R., and Lincoln P. Bloomfield. CASCON: Computer-Aided System to Handle Information on Local Conflicts. Cambridge, Mass.: Center for International Studies, MIT, 1969.

Bloomfield, Lincoln P., et al. Anticipating ConflictControl Policies - The "CONEX" Games as a Planning Tool. Cambridge, Mass.: Center for International Studies, MIT, 1970.

- and Amelia C. Leiss. Controlling Small Wars: A Strategy for the 1970's. New York: Knopf, 1969.

- - The Control of Local ConflictA Design Study on Arms Control and Limited War in the Developing Areas. Washington: US Government Printing Office, 1967.

Boulding, Kenneth. Conflict and Defense. New York: Harper and Row, 1963.

Browne and Shaw International Division. The Control of Local Conflict: Case Studies. Cambridge, Mass.: Bolt, Beranek and Newman, 1969.

Hermann, Charles. Crisis in Foreign Policy. New York: Bobbs-Merrill, 1969.

Leiss, Amelia C., and Lincoln P. Bloomfield. Con- trol of Conflict: A Design Study on Arms Control and Limited War in the Developing Areas: Studies of Conflict. Washington: US Government Printing Office, 1967.

Raser, John R. Simulation and Society. Boston: Allyn and Bacon, 1969.

Young, Oran R. The Politics of Force. Princeton: Princeton University Press, 1968.

Wright, Quincy. "Escalation of International Conflicts," Journal of Conflict Resolution, 1965, 9 (4, Dec.).

\section{APPENDIX}

CASES IN THE INITIAL CASCON DATA BASE

\begin{tabular}{l}
\hline Algerian Civil War: 1954-1962 \\
Algerian-Moroccan Conflict: 1962-1963 \\
Angolan Conflict: 1950-1961 \\
Bay of Pigs: 1960-1961 \\
Bolivian Conflict: 1967 \\
Cuban Insurgency: 1952-1959 \\
Conflict on Cyprus (Enosis): 1954-1959 \\
Dominican Republic Conflict: 1963-1965 \\
Greek Insurgency: 1944-1949 \\
Guatemala Conflict: 1953-1954 \\
India-China Border Conflict: 1954-1962 \\
Indonesian-Malaysian Confrontation: 1963-1965 \\
Indonesian War of Independence: 1945-1949 \\
Iraq-Kurds Conflict: 1959-1963 \\
Kashmir Conflict: 1947-1949* \\
Kuwait-Iraq Conflict: 1961 \\
Lebanon Conflict: 1958 \\
Malayan Emergency: 1948-1960 \\
Philippines-Huk Conflict: 1946-1954 \\
Quemoy-Matsu Conflict: 1954-1958 \\
Sinai Conflict: 1956 \\
Somalia-Ethiopia-Kenya Conflict: 1960-1964 \\
Suez Conflict: 1956 \\
Soviet-Iranian Conflict: 1941-1947 \\
Venezuela Conflict: 1960-1963 \\
West Irian Conflict: 1962-1963 \\
Yemeni Civil War: 1962-1969
\end{tabular}

*The Kashmir Conflict, 1949-1965, although part of the Design Study is not included in CASCON. 